\title{
Adsorption of Co(II) on Graphene Oxides from Aqueous Solution
}

\author{
Hua Zhu ${ }^{1, *}$, Xuetao $\mathrm{Xu}^{2}$, Xin Zhong1 \\ ${ }^{1}$ School of Chemistry and Chemical Engineering, Sichuan University of Arts and Sciences, \\ Dazhou 635000, P.R. China \\ ${ }^{2}$ School of Chemical and Environmental Engineering, Wuyi Unicersity, \\ Jiangmen 529020, P.R. China
}

Received: 20 April 2016

Accepted: 15 June 2016

\begin{abstract}
Graphene oxide (GO) was synthesized and characterized by scanning electron microscopy (SEM), transmission electron microscopy (TEM), x-ray diffraction (XRD), and Fourier transformed infrared spectra (FT-IR). The adsorption of $\mathrm{Co}$ (II) on GO was studied as a function of contact time, $\mathrm{pH}$, ionic strength, humic acid, $\mathrm{Co}(\mathrm{II})$ concentration, and temperature. The adsorption of $\mathrm{Co}(\mathrm{II})$ is strongly dependent on the $\mathrm{pH}$ values and weakly dependent on ionic strength. The adsorption thermodynamics of $\mathrm{Co}$ (II) on GO was carried out at 303,313 , and $333 \mathrm{~K}$ to obtain the corresponding thermodynamic data $\left(\Delta \mathrm{H}^{0}, \Delta S^{0}\right.$, and $\left.\Delta \mathrm{G}^{0}\right)$, which suggested that the adsorption of $\mathrm{Co}(\mathrm{II})$ on $\mathrm{GO}$ is a spontaneous and endothermic process. GO provided a promising candidate for the preconcentration and solidification of $\mathrm{Co}(\mathrm{II})$ from large volumes of aqueous solutions.
\end{abstract}

Keywords: graphene oxide, adsorption, Co(II), humic acid

\section{Introduction}

Heavy-metal ion pollution is a worldwide environmental concern due to the indiscriminate disposal of industrial wastewater from mining, metallurgical, chemical, and battery production, plus other sources [17]. Cobalt is one of the most toxic metals that affects the environment. The increasing consumption of radionuclides ${ }^{60} \mathrm{Co}$ and ${ }^{58} \mathrm{Co}$ in nuclear power plants and other related industries has exaggerated its environmental pollution [3, 8-11]. As an indispensable element to the human body, $\mathrm{Co}$ (II) has played a vital role in the immune system. However, excessive exposure could also cause serious health problems $[8-9,12]$, such as polycythemia, diarrhea, nasopharyngitis, gastrointestinal disorders, and

*e-mail: zhuhua2006@163.com so on. Thus it is necessary to remove toxic Co(II) from wastewater before releasing it into the environment.

Various methods, including coprecipitation, precipitation, oxidation, ion-exchange, membrane electrolysis, reverse osmosis, and adsorption, have been employed during the past decades to remove toxic metal ions, including $\mathrm{Co}(\mathrm{II})$, from large volumes of aqueous solution [8-9, 11, 13]. Among these methods, the adsorption technique has been used widely because of its simple, economical, and cost-effective characteristics. Adsorbents such as clay minerals, carbon materials, polymer materials, and oxides have been studied extensively [8, 11-16]. However, these materials suffer from either low efficiencies or low adsorption capacities. Recently, carbon nanomaterials such as graphene [17-21], carbon nanotube, and its related composited material $[8,10,22-25]$ have been introduced to the adsorption areas because of their 
high surface area, high stability, enhanced active sites, and abundant functional groups.

Graphene, a kind of one or several atomic-layered graphite, possesses special two-dimensional structure, and excellent mechanical, thermal, and electrical properties [26-27].

Considering the high surface area and the abundant oxygen-containing functional groups of graphene oxide (GO), the amphiphilic GO stable suspensions might have high adsorption capacity to preconcentrate heavy metal ions from aqueous solutions [16, 28-30]. Previous research has shown that GO can effectively remove of metal ions such as $\mathrm{Cu}(\mathrm{II}), \mathrm{Eu}(\mathrm{III}), \mathrm{Cd}(\mathrm{II}), \mathrm{U}(\mathrm{VI}), \mathrm{Ni}(\mathrm{II})$, and arsenate using its surface functionalized hydroxyl and carboxyl groups, which are well-suited for their interactions with metal ions. Besides, humic acids (HA) are also found to have strong complexation abilities with metal ions [11, 23, 31-33]. Although GO has been widely studied regarding its interactions with heavy metal ions, few studies have been devoted to the adsorption behaviors of metal ions on graphene oxide nanosheets in the presence of HA.

This work presents the application of GO for the effective removal of $\mathrm{Co}(\mathrm{II})$ from aqueous solutions. The preparation of GO nanosheets, the kinetics of adsorption, the effects of $\mathrm{pH}$, ionic strength, and the effects of HA and temperature on $\mathrm{Co}$ (II) adsorption capacities were studied in batch adsorption modes to illustrate the performance of GO to remove $\mathrm{Co}$ (II) from aqueous solutions. A mechanism for $\mathrm{Co}$ (II) interaction with $\mathrm{GO}$ nanosheets was also proposed.

\section{Materials and Methods}

GO was prepared according to [16]. Humic acid (HA) was extracted from a soil sample obtained from Hua-Jia County in Gansu Province, China $\left(35^{\circ} \mathrm{N}\right.$ and $105^{\circ} \mathrm{E}$ ), which is close to the site of a nuclear weapons test site and a nuclear waste repository [33]. The main constituents of the extracted HA are: C $60.44 \%$, H 3.53\%, $\mathrm{N} 4.22 \%$, O 31.31\%, and S $0.50 \%$ [35]. Co(II) stock solution, $300 \mathrm{mg} / \mathrm{L}$, was prepared by dissolving $\mathrm{CoCl} 2$ (purity $>99.9 \%$ ) in distilled Milli-Q water [32]. All reagents used in the batch experiments were purchased in analytical purity and used directly without any further purification. All reagents were prepared with Milli-Q water.

\section{Characterization of GO Nanosheets}

GO nanosheets were characterized by scanning electron microscopy (SEM), transmission electron microscopy (TEM), powder x-ray diffraction (XRD), and Fourier transformed infrared spectra (FT-IR). SEM and TEM investigations were carried out on JSM-6320F FESEM and JEOL JEM-2000EX microscopes, respectively. The XRD patterns were measured on a $\mathrm{D} / \max 2500$ with a $\mathrm{Cu} \mathrm{K \alpha}$ source $(\lambda=1.541 \AA)$. FT-IR spectroscopy was obtained from a Perkin Elmer 100 spectrometer in $\mathrm{KBr}$ pellet under environmental condition.

\section{Adsorption Experiments}

All the experiments were carried out using a batch technique according to a literature procedure [10]. The adsorption percentage and the distribution coefficient $\left(K_{d}\right)$ are calculated from the following equations:

$$
\begin{gathered}
K_{d}=\frac{C_{0}-C_{e}}{C_{e}} \times \frac{V}{m} \\
\text { Sorption } \%=\frac{C_{0}-C_{e}}{C_{0}} \times 100 \%
\end{gathered}
$$

...where $C 0(\mathrm{mg} \cdot \mathrm{L}-1)$ is the initial concentration, $C e$ $(\mathrm{mg} \cdot \mathrm{L}-1)$ is the equilibrium concentration, $m(\mathrm{~g})$ is the mass of $\mathrm{GO}$, and $V(\mathrm{~L})$ is the volume of suspension. The presented data were the average values of duplicate or triplicate determinations and the relative errors of the data were within $5 \%$.

\section{Results and Discussion}

\section{Characterization}

The detailed characterization of the as-prepared GO nanosheets was collected in Fig. 1. The TEM image (Fig. 1a) indicates the formation of a GO nanosheet with a few layers. The surface morphology can be obtained from the SEM image with typically wrinkle- and crumple-like structures (Fig. 1b).

In the XRD patterns (Fig. 1c), the formation of GO nanosheets are confirmed by the disappeared diffraction peak at $2 \theta=26.40^{\circ}(\mathrm{d}=0.34 \mathrm{~nm})$ and the new observed broad and relatively weak diffraction peak at $2 \theta=10.03^{\circ}$ $(\mathrm{d}=0.87 \mathrm{~nm})$. The $\mathrm{c}$-axis spacing increases from $0.34 \mathrm{~nm}$ to $0.87 \mathrm{~nm}$ after the graphite is modified to $\mathrm{GO}$ nanosheets, which is attributed to the surface-abundant oxygencontaining functional groups of GO nanosheets [16-17].

The oxygen-containing functional groups on the surfaces of GO nanosheets are further characterized by FT-IR analysis (Fig. 1d). Peaks found at 1,730 $\mathrm{cm}^{-1}$ $(\mathrm{C}=\mathrm{O}$ stretch $), 1,620 \mathrm{~cm}^{-1}(\mathrm{C}=\mathrm{C}$ stretch $)$, and $1,220 \mathrm{~cm}^{-1}$ and $1,100 \mathrm{~cm}^{-1}$ (C-O stretch) indicate the successful oxidation of graphite to GO nanosheets [21, 29].

\section{Time-dependent Adsorption}

The adsorption of $\mathrm{Co}$ (II) by $\mathrm{GO}$ nanosheets from aqueous solution as a function of contact time is shown in Fig. 2. A rapid increment of $\mathrm{Co}$ (II) adsorption is observed 
during the first $20 \mathrm{~min}$. and then it remains constant as contact time increases. It is necessary to point out that the time in $\mathrm{x}$-axis is shaking time, and the centrifuge time (20 $\min$ ) is not counted. Fast adsorption may be attributed to the strong surface complexation or chemical adsorption of $\mathrm{Co}(\mathrm{II})$ by GO nanosheets. This rapid adsorption equilibrium is significant for the potential industrial application to remove $\mathrm{Co}$ (II) from a large volume of aqueous solution by GO nanosheets. The detailed adsorption rate of $\mathrm{Co}$ (II) adsorption on GO nanosheets can be analyzed by applying a pseudo-second-order rate equation to simulate kinetic adsorption [36].

$$
\frac{t}{q_{t}}=\frac{1}{2 K^{\prime} q_{e}{ }^{2}}+\frac{t}{q_{e}}
$$

...where $K^{\prime}\left(\mathrm{g}^{\mathrm{mg}} \mathrm{m}^{-1} \cdot \mathrm{min}^{-1}\right)$ is the pseudo-second-order rate constant of adsorption, $q_{t}\left(\mathrm{mg} \cdot \mathrm{g}^{-1}\right)$ is the amount of $\mathrm{Co}$ (II) adsorbed by GO at time $t(\mathrm{~min})$, and $q_{e}\left(\mathrm{mg} \cdot \mathrm{g}^{-1}\right)$ stands for the equilibrium adsorption capacity. A linear plot feature of $t / q_{t}$ to $t$ is achieved and shown in Fig. 2. The rate constant, $K^{\prime}$, is calculated to be $0.30 \mathrm{~g} \cdot \mathrm{mg}^{-1} \cdot \mathrm{min}^{-1}$ with a high correlation coefficient, $R^{2}=0.9929$, confirming the
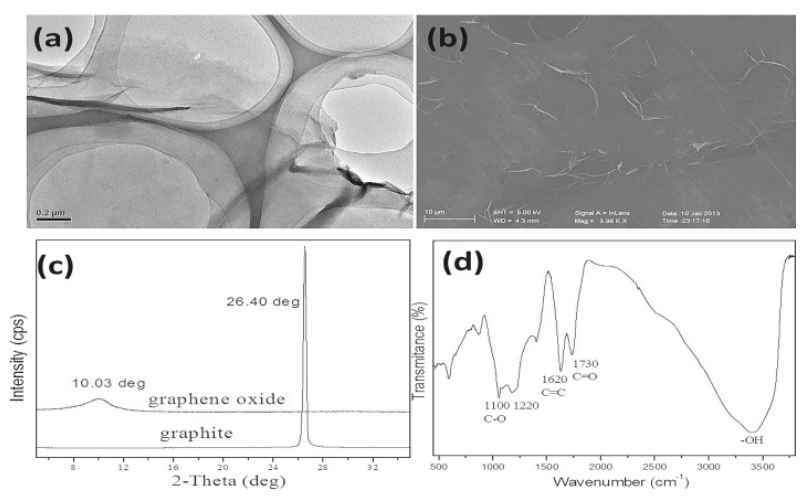

Fig. 1. TEM image of GO a), SEM image of GO b), XRD image of GO and graphite c), and FT-IR spectrum of GO d).

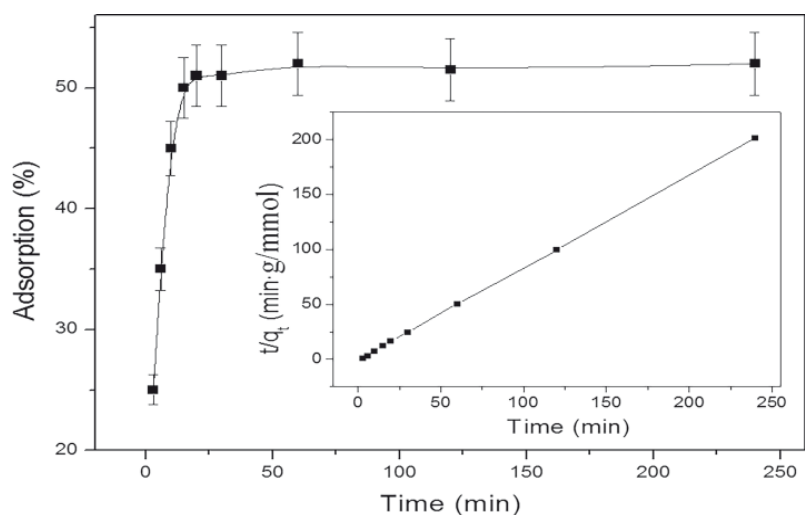

Fig. 2. Effect of contact time on Co(II) sorption by GO, $\mathrm{pH}=6.8 \pm 0.1, T=303.15 \mathrm{~K}, m / V=0.1 \mathrm{~g} / \mathrm{L}, C_{\text {[Co(II)]initial }}=$ $1.69 \times 10^{-4} \mathrm{~mol} / \mathrm{L}$, and $I=0.01 \mathrm{M} \mathrm{NaClO}_{4}$. viability of the pseudo-second-order rate equation to this adsorption system.

\section{Effect of GO Nanosheet Concentration}

Fig. 3 displays the effect of GO nanosheet concentration to $\mathrm{Co}$ (II) sorption. It can be seen that the adsorption percentage of $\mathrm{Co}$ (II) increases rapidly from $10 \%$ to $85 \%$ as the GO nanosheet concentration increases from 0.025 to $0.30 \mathrm{~g} / \mathrm{L}$ at $\mathrm{pH}$ 6.8, which can be explained by the more available surface sites on GO nanosheet for $\mathrm{Co}$ (II) adsorption. Meanwhile, the distribution coefficient, $K_{d}$, decreases as the GO nanosheet concentration increases. This phenomenon is observed due to the complexation of $\mathrm{Co}(\mathrm{II})$ with $\mathrm{GO}$ nanosheets to produce GO nanosheet aggregates [16, 18, 28]. At high GO nanosheet concentration, the size and concentration of GO-Co(II) aggregates increases, which may reduce or block the complexation between $\mathrm{Co}$ (II) ions and GO nanosheets, resulting in a decreased $K_{d}$ value. Similar phenomena were also found for the sorption of $\mathrm{Eu}(\mathrm{III})$, Th(IV), and U(VI) on graphene oxides [5, 37-39].

\section{Effect of $\mathrm{pH}$}

The importance of $\mathrm{pH}$ values on $\mathrm{Co}(\mathrm{II})$ adsorption by GO nanosheets is shown in Fig. 4, which can be explained by the change of the surface properties of sorbents and the hydrolysis, precipitation, and complexation of $\mathrm{Co}$ (II) at different $\mathrm{pH}$ values $[10,13,21]$. As can be seen from Fig. 4, the adsorption of $\mathrm{Co}$ (II) increases as $\mathrm{pH}$ ranges from 4.0 to 6.0 , followed by a sharp increase at $\mathrm{pH}$ 6.0-8.5. Finally, the adsorption maintains a high value at $\mathrm{pH}>8.5$. More than $95 \%$ of $\mathrm{Co}$ (II) can be removed from the solution at $\mathrm{pH}>8.5$. The strong $\mathrm{pH}$-dependent sorption suggests that $\mathrm{Co}$ (II) sorption on the $\mathrm{GO}$ is attributed to surface complexation rather than ion exchange.

This observed phenomenon can be attributed to the hydrolysis of $\mathrm{Co}$ (II) in aqueous solution, of which the relative species distribution of $\mathrm{Co}$ (II) calculated from the hydrolysis constants $\left(\log K_{1}=-19.6, \log K_{2}=-9.2\right.$, and $\left.\log K_{3}=-2.7\right)$ is shown in Fig. 4a [40]. Co(II) presents with different forms as $\mathrm{Co}^{2+}, \mathrm{Co}(\mathrm{OH})^{+}, \mathrm{Co}(\mathrm{OH})_{2}$, and $\mathrm{Co}(\mathrm{OH})_{3}^{-}$at different $\mathrm{pH}$ values. At $\mathrm{pH}<8.5$, the main species are $\mathrm{Co}^{2+}$ and $\mathrm{Co}(\mathrm{OH})^{+}$. However, when $\mathrm{pH}>8.5$ the adsorption of $\mathrm{Co}$ (II) in this system is getting complex. As shown in Fig. 4c, the zeta potential of GO is highly negatively charged and the negative charges would be further enhanced. The density of protonated sites $\left(\equiv \mathrm{SOH}_{2}^{+}\right.$, where $\equiv \mathrm{SOH}$ represents the surface of graphene oxide, and $-\mathrm{OH}$ indicates the oxygen-containing functional groups) decreases with increasing $\mathrm{pH}$ because of the protonation reaction (i.e., $\equiv \mathrm{SOH}+\mathrm{H}^{+} \leftrightarrow \equiv \mathrm{SOH}_{2}^{+}$) on the surface of the GO. Thereby, the adsorption of $\mathrm{Co}^{2+}$ and $\mathrm{Co}(\mathrm{OH})^{+}$on the surface of $\mathrm{GO}$ is unfavorable as a result of Coulombic repulsion at $\mathrm{pH}$ ranging from 2.0 to 5.0. However, at high $\mathrm{pH}$ values the concentration of deprotonated sites $(\equiv \mathrm{SO})$ increases because of the surface deprotonation reaction (i.e., $\equiv \mathrm{SOH} \leftrightarrow \equiv \mathrm{SO}^{-}+\mathrm{H}^{+}$). More deprotonated sites $(\equiv \mathrm{SO}$ ) 


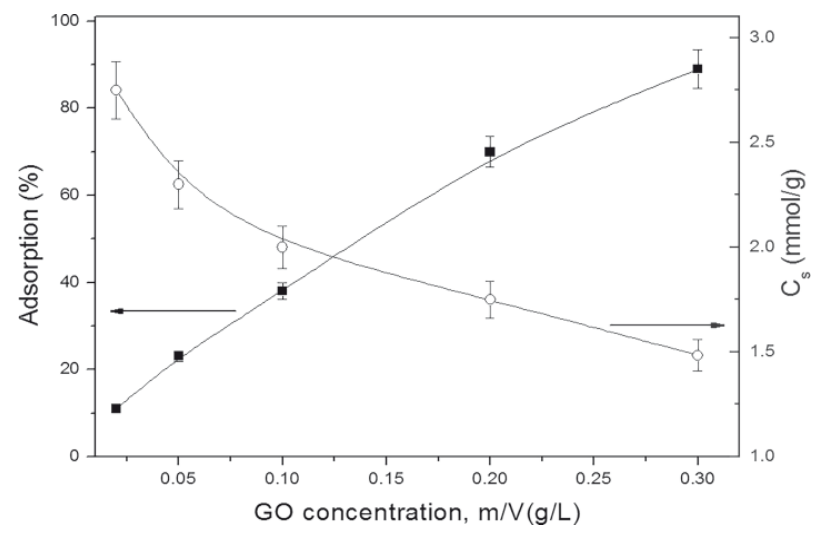

Fig. 3. Effect of GO concentration on Co(II) adsorption by GO, $\mathrm{pH}=6.8 \pm 0.1, T=303.15 \mathrm{~K}, C_{\text {[Co(II)]initial }}=1.69 \times 10^{-4} \mathrm{~mol} / \mathrm{L}$, $I=0.01 \mathrm{M} \mathrm{NaClO}_{4}$.
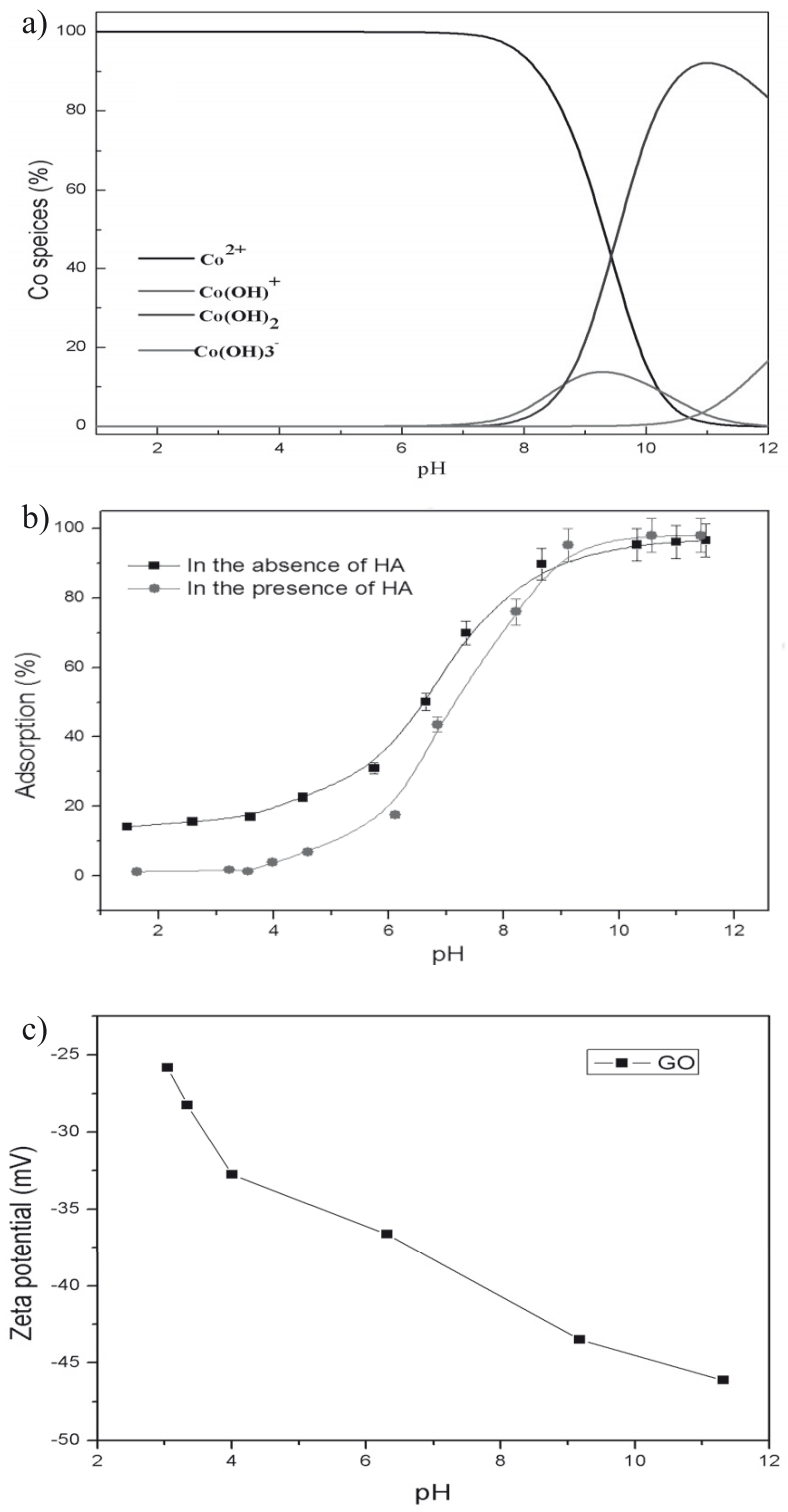

Fig. 4 The distribution of $\mathrm{Co}$ (II) at different $\mathrm{pH}$ values a), effect of $\mathrm{pH}$ and $\mathrm{HA}$ on $\mathrm{Co}$ (II) adsorption by GO b), and the zeta potential of GO c), $T=303.15 \mathrm{~K}, m / V=0.1 \mathrm{~g} / \mathrm{L}, C_{[\mathrm{Co}(I)] \text { intitial }}=$ $1.69 \times 10^{-4} \mathrm{~mol} / \mathrm{L}, I=0.01 \mathrm{M} \mathrm{NaClO}_{4}$. are available to retain the metal ions and form surface complexation with $\mathrm{Co}^{2+}$ and $\mathrm{Co}(\mathrm{OH})^{+}$, resulting in a sharp increase of $\mathrm{Co}(\mathrm{II})$ adsorption at $\mathrm{pH}$ 5.0-8.5. Precipitation of $\mathrm{Co}(\mathrm{OH})_{2}$ begins to form at $\mathrm{pH}>8.5$ and reaches a maximum value at about 10.5. Therefore, the adsorption of $\mathrm{Co}$ (II) is accomplished by surface complexation and precipitation $[8,10]$.

\section{Effect of Ionic Strength}

The influence of ionic strength on the adsorption of $\mathrm{Co}(\mathrm{II})$ by $\mathrm{GO}$ nanosheets is investigated by screening different concentrations of $\mathrm{NaClO}_{4}$ solutions. As shown in Fig. 5, the adsorptions of $\mathrm{Co}$ (II) are weakly dependent on $\mathrm{NaClO}_{4}$ concentrations. The sorption curves shift to left at lower $\mathrm{NaClO}_{4}$ concentrations as compared to those at higher $\mathrm{NaClO}_{4}$ concentrations, indicating an inhibition adsorption of $\mathrm{Co}$ (II) by GO nanosheet at high ionic strength. The ionic strength can influence the thickness and interface potential of the solution and surface layers of the GO nanosheet, as well as the binding of the adsorbing species. The background electrolyte ions are considered in the same platform as the surface complexation, thus surface complexations are expected to be more susceptible to vary ionic strength than ion exchange. Consequently, the sorption of $\mathrm{Co}$ (II) by GO nanosheets may suggest the formation of surface complexation on the surfaces of the GO [18, 41]. The effect of ionic strength on $\mathrm{Co}$ (II) adsorption is more obvious at low $\mathrm{pH}$ compared to high $\mathrm{pH}$. Thus it can be concluded that $\mathrm{Co}$ (II) adsorption by GO nanosheets are mainly attributed to surface complexation at low $\mathrm{pH}$, and a simultaneous precipitation or surface complexation at high $\mathrm{pH}$ values $[16,42]$.

\section{Effect of Humic Acid}

Effect of HA on Co(II) adsorption by GO nanosheets is displayed in Fig. 4. The presence of HA reduces $\mathrm{Co}$ (II) adsorption at $\mathrm{pH}<8$, but no obvious differences are detected when $\mathrm{pH}>8$. For most materials (such as clay minerals, oxides, and carbon nanotubes), HA enhances metal ion adsorption on solid phase at low $\mathrm{pH}$ values, and reduces metal ion adsorption at high $\mathrm{pH}$ values [39, 43]. The increase of metal ion adsorption at low $\mathrm{pH}$ values is generally attributed to the strong complexation of metal ions with HA adsorbed on solid particles, whereas the decrease of metal ion adsorption is interpreted by the formation of soluble metal-HA complexes in aqueous solution. Herein, HA decreases Co(II) adsorption by GO nanosheets at $\mathrm{pH}<8$, which may be attributed to the strong surface complexation and high surface site density of GO, which is calculated to be $2.36 \times 10^{-3} \mathrm{~mol} / \mathrm{g}$ by acid-base titration, whereas the value is $6.46 \times 10^{-3} \mathrm{~mol} / \mathrm{g}$ for $\mathrm{HA}$ [38]. The high surface site density of GO nanosheets assures the high adsorption of $\mathrm{Co}$ (II) ions on the surface of GO. HA can be bound to GO through strong $\pi-\pi$ interactions and interact with $\mathrm{GO}$ in aquatic systems, thereby changing greatly their properties in such systems [44-45]. Although 
the surface sites density of GO is lower than that of HA, the strong interaction of GO with HA occupies parts of surface sites on the surface of GO and also reduces the available binding sites of HA, thereby resulting in the decrease of $\mathrm{Co}$ (II) adsorption on GO. It is necessary to note that the effect of HA on $\mathrm{Co}$ (II) adsorption at $\mathrm{pH}>8$ is not obvious, which is attributed to the formation of $\mathrm{Co}(\mathrm{OH})_{2}$, precipitation at $\mathrm{pH}>8.2$.

\section{Effect of Temperature and Thermodynamic study}

Thermodynamic parameters are helpful in practical applications. The sorption isotherms of GO nanosheets at different temperatures are collected in Fig. 6 in order to investigate the impact factor of temperatures. The adsorption of $\mathrm{Co}$ (II) increases with elevated temperature with a maximum value at $T=333 \mathrm{~K}$ and a minimum value at $T=303 \mathrm{~K}$, illustrating an endothermic process of Co(II) sorption by GO nanosheets. The thermodynamic parameters $\left(\Delta \mathrm{G}^{0}, \Delta \mathrm{S}^{0}\right.$, and $\left.\Delta \mathrm{H}^{0}\right)$ are calculated from the temperature-dependent adsorption isotherms. The Gibbs free energy change is derived from the equation:

$$
\Delta G^{0}=-R T \ln K^{0}
$$

...where $K^{0}$ is the constant of adsorption equilibrium, and values of $\ln K^{0}$ stand for the adsorption abilities of GO toward $\mathrm{Co}(\mathrm{II})$, which are obtained by plotting $\ln K_{d}$ versus $C_{e}$, followed by extrapolating $C_{e}$ to zero as shown in Fig. 7. Standard entropy change $\left(\Delta \mathrm{S}^{0}\right)$ is then derived from the relationship:

$$
\Delta S^{0}=-\left(\frac{\partial \Delta G^{0}}{\partial T}\right)
$$

The average standard enthalpy change $\left(\Delta \mathrm{H}^{0}\right)$ can be obtained from the equation:

$$
\Delta \mathrm{H}^{0}=\Delta \mathrm{G}^{0}+T \Delta S^{0}
$$

The values calculated from the thermodynamic equations are listed in Table 1 . The positive value of $\Delta \mathrm{H}^{0}$ indicates an endothermic sorption process, which is consistent with our previous observations. A reasonable interpretation concerns the completely solvated $\mathrm{Co}$ (II) ions in water. The hydration sheath of Co(II) is supposed to be destroyed before being adsorbed by GO nanosheets, and the desolvated energy exceeds the released energy when adsorbed by GO nanosheets, resulting in an endothermic process favored by high temperatures $[6,31]$. However, the entropy changes compensate the enthalpy changes, resulting in a negative value of the Gibbs free energy change $\left(\Delta \mathrm{G}^{0}\right)$ and a spontaneous process at the conditions applied. The positive value of the entropy change $\left(\Delta \mathrm{S}^{0}\right)$ may be attributed to the structure change of the composite complex $[37,46]$. As the temperature rises, $\mathrm{Co}(\mathrm{II})$ cations are more likely to be desolvated and the adsorption becomes more favorable. In short, the adsorption of $\mathrm{Co}$ (II) on $\mathrm{GO}$ is an endothermic and spontaneous process.

The sorption mechanism of $\mathrm{Co}$ (II) on GO were further simulated by Langmuir and Freundlich models.

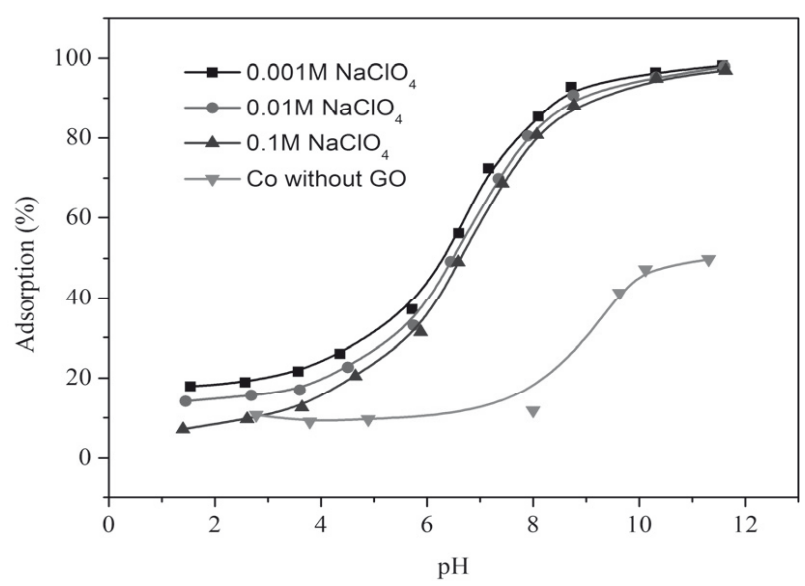

Fig. 5. Effect of ionic strength on $\mathrm{Co}(\mathrm{II})$ adsorption by GO, $T=303.15 \mathrm{~K}, m / V=0.1 \mathrm{~g} / \mathrm{L}, C_{\text {[Co(II)] initial }}=1.69 \times 10^{-4} \mathrm{~mol} / \mathrm{L}$.

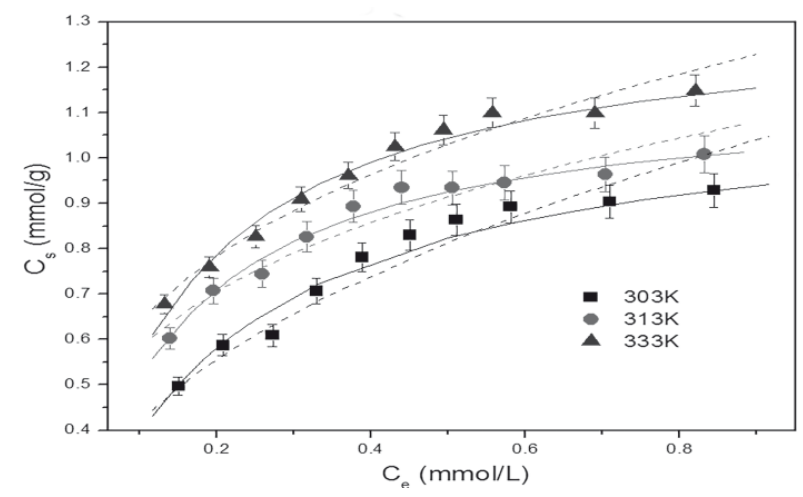

Fig. 6. Sorption isotherms of $\mathrm{Co}(\mathrm{II})$ to $\mathrm{GO}$ at three different temperatures. The solid line stands for Langmuir model and the dotted line stands for Freundlich model; $\mathrm{pH}=6.8 \pm 0.1$, $m / V=0.1 \mathrm{~g} / \mathrm{L}, I=0.01 \mathrm{M} \mathrm{NaClO}_{4}$.

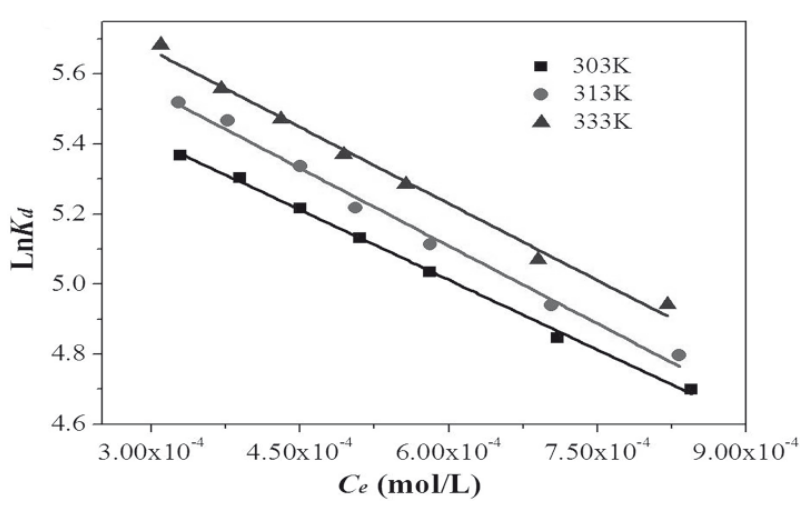

Fig. 7. Linear plots of $\ln K_{d}$ versus $C_{e} \cdot \mathrm{pH}=6.8 \pm 0.1$, $m / V=0.1 \mathrm{~g} / \mathrm{L}, I=0.01 \mathrm{M} \mathrm{NaClO}_{4}$. 
Table 1. Parameters of adsorption isotherms.

\begin{tabular}{|c|c|c|c|}
\hline & $\Delta G^{0}(\mathrm{~kJ} / \mathrm{mol})$ & $\Delta H^{0}(\mathrm{~kJ} / \mathrm{mol})$ & $\Delta S^{0}(\mathrm{~J} / \mathrm{mol} / \mathrm{K})$ \\
\hline $303 \mathrm{~K}$ & -14.64 & & 75.30 \\
\hline $313 \mathrm{~K}$ & -15.61 & \multirow{2}{*}{8.176} & 75.99 \\
\hline $333 \mathrm{~K}$ & -16.90 & & 75.30 \\
\hline
\end{tabular}
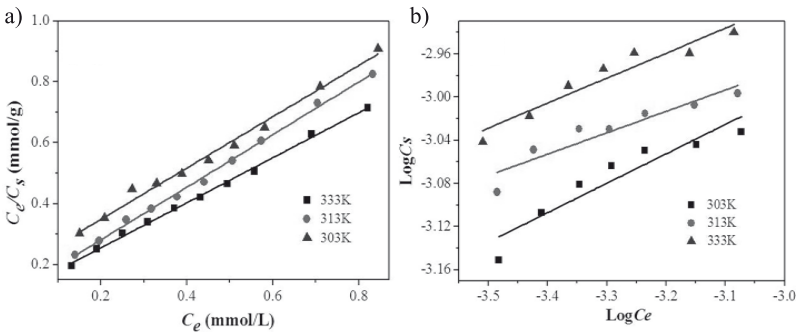

Fig. 8. Langmuir (a) and Freundlich (b) isotherms of $\mathrm{Co}(\mathrm{II})$ sorption by $\mathrm{GO}$ at three different temperatures; $\mathrm{pH}=6.8 \pm 0.1, m / V=0.1 \mathrm{~g} / \mathrm{L}, I=0.01 \mathrm{M} \mathrm{NaClO}_{4}$

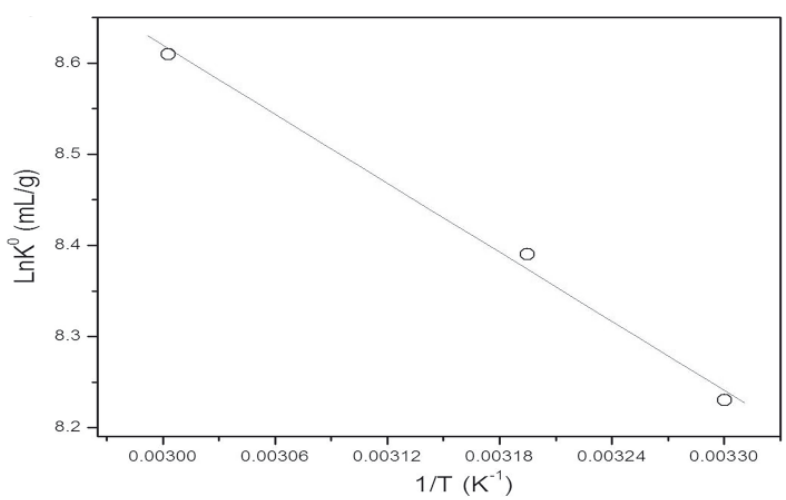

Fig. 9. Linear plot of $\operatorname{lnK} \mathrm{K}^{0}$ vs. $1 / \mathrm{T}$ for the sorption of $\mathrm{Co}(\mathrm{II})$ by GO nanosheets at 303,313 , and $333 \mathrm{~K} ; m / V=0.1 \mathrm{~g} / \mathrm{L}, \mathrm{pH}=6.8$, $I=0.01 \mathrm{M} \mathrm{NaClO}_{4}$.

The Langmuir isotherm model was applied to describe the monolayer adsorption process. It can be expressed by equation 7 [47]:

$$
C_{s}=\frac{b C_{s \max } C_{e}}{1+b C_{e}}
$$

...where $C_{e}$ is the equilibrium concentration of $\mathrm{Co}$ (II) remaining in adsorption $\left(\mathrm{mol} \cdot \mathrm{g}^{-1}\right), C_{s} \max \left(\mathrm{mol} \cdot \mathrm{g}^{-1}\right)$ (maximum adsorption capacity) stands for the amount of $\mathrm{Co}$ (II) adsorbed at complete monolayer coverage, and $b\left(\mathrm{~L} \cdot \mathrm{mol}^{-1}\right)$ is a Langmuir constant that relates to the adsorption heat.

A linear form can be obtained from equation 7 :

$$
\frac{C_{e}}{C_{s}}=\frac{1}{b C_{s \max }}+\frac{C_{e}}{C_{s \max }}
$$

The Freundlich isotherm model, which is applicable to several kinds of adsorption on solid surface, fits the adsorption data at low and medium concentrations properly on heterogeneous surfaces. The model has the following form [9]:

$$
C_{s}=K_{F} C_{e}^{n}
$$

Equation 9 can be expressed in linear form:

$$
\log C_{s}=\log K_{F}+n \log C_{e}
$$

$K_{F}\left(\mathrm{~mol}^{1-\mathrm{n} \cdot} \cdot \mathrm{L}^{\mathrm{n}} \cdot \mathrm{g}^{-1}\right)$ and $n$ are Freundlich constants, representing the adsorption capacity when metal ion equilibrium concentration equal 1 and adsorption intensity, respectively.

The analysis results that applied to the Langmuir and Freundlich models are shown in Fig. 8. Relative parameters of the models are listed in Table 2 . The highest correlation coefficients $\left(R^{2}\right)$ are obtained by the Langmuir model at three different temperatures as compared to Freundlich. Meanwhile, the fact that a high temperature contributes to the adsorption capacity can be induced from the phenomenon that the values of $C_{s \max }$ calculated from the Langmuir model for Co(II) adsorption on GO are the lowest at $T=303 \mathrm{~K}$, while the highest are at $T=333 \mathrm{~K}$. The isotherms at different temperatures for $\mathrm{GO}$ are shown in Fig. 9. It is also clear that the sorption isotherm is the lowest at $T=303 \mathrm{~K}$ and the highest at $T=333 \mathrm{~K}$, suggesting that the sorption process is favored at a high temperature. Hence the sorption reaction is an endothermic process. The maximum adsorption capacity of $\mathrm{GO}$ at $T=303 \mathrm{~K}$ is calculated to be $1.13 \mathrm{mmol} \cdot \mathrm{g}^{-1}$ (66.67 $\left.\mathrm{mg} \cdot \mathrm{g}^{-1}\right)$. Compared with previous reported adsorbents such as raw carbon nanotube $\left(0.034 \mathrm{mmol} \cdot \mathrm{g}^{-1}\right)$ [10], oxide carbon nanotube $\left(0.147 \mathrm{mmol} \cdot \mathrm{g}^{-1}\right)$ [8], activated

Table 2. Parameters of Langmuir and Freundlich models.

\begin{tabular}{|c|c|c|c|c|c|c|}
\hline & \multicolumn{3}{|c|}{ Langmuir } & \multicolumn{3}{c|}{ Freundlich } \\
\hline $\mathrm{Co}(\mathrm{II}), \mathrm{pH}=6.8$ & $C s(\mathrm{mg} / \mathrm{g})$ & $b(\mathrm{~L} / \mathrm{mg})$ & $R^{2}$ & $K_{F}\left(\mathrm{mg}^{1-\mathrm{n}} \cdot \mathrm{L}^{\mathrm{n}} / \mathrm{g}\right)$ & $n$ & $R^{2}$ \\
\hline $\mathrm{T}=303 \mathrm{~K}$ & 66.67 & 0.097 & 0.993 & 19.49 & 0.2726 & 0.887 \\
\hline $\mathrm{T}=313 \mathrm{~K}$ & 68.09 & 0.143 & 0.997 & 27.98 & 0.1979 & 0.879 \\
\hline $\mathrm{T}=333 \mathrm{~K}$ & 79.36 & 0.121 & 0.997 & 28.06 & 0.2312 & 0.923 \\
\hline
\end{tabular}


carbon (13.879 $\left.\mathrm{mg} \cdot \mathrm{g}^{-1}\right)$ [48], $\mathrm{Ti}_{2} \mathrm{O}\left(0.338 \mathrm{mmol} \cdot \mathrm{g}^{-1}\right)$ [15], iron oxides $\left(5.03 \mathrm{mg} \cdot \mathrm{g}^{-1}\right)[49]$, hydroxyapatite $\left(0.134 \mathrm{mmol} \cdot \mathrm{g}^{-1}\right)[50]$, fruit shell $\left(0.34 \mathrm{mg} \cdot \mathrm{g}^{-1}\right)$ [51], and zeolite $\left(1.242 \mathrm{mmol} \cdot \mathrm{g}^{-1}\right)$ [52], GO nanosheets exhibit promising potential applications as adsorbents in nuclear waste management if synthesized on a large scale and at a low future price.

\section{Conclusions}

The adsorption of $\mathrm{Co}(\mathrm{II})$ by GO nanosheets was studied under ambient conditions. The effects of contact time, $\mathrm{pH}$, ionic strength, humic acid, and temperature were investigated. The kinetic sorption process can be well described by the pseudo-second-order model for the adsorbents. The adsorption of Co(II) by GO nanosheets is highly dependent on $\mathrm{pH}$ values. The thermodynamic parameters indicate that the interaction of $\mathrm{Co}$ (II) adsorbed by GO is endothermic and spontaneous. The main adsorption mechanism for $\mathrm{Co}$ (II) adsorbed on GO nanosheets is probably the complexation of $\mathrm{Co}$ (II) with the surface-abundant oxygen-containing functional groups. Together, GO nanosheets exhibit promising potential applications as adsorbents in nuclear waste management.

\section{References}

1. MORENO-CASTILLA C., ALVAREZ-MERINO M. A., LOPEZ-RAMON M. V., RIVERA-UTRILLA J. Cadmium ion adsorption on different carbon adsorbents from aqueous solutions. effect of surface chemistry, pore texture, ionic strength, and dissolved natural organic matter. Langmuir, 20, $8142,2004$.

2. LI J., GUO Z., ZHANG S., WANG X. Enrich and seal radionuclides in magnetic agarose microspheres. Chem. Eng. J., 172 (2-3), 892, 2011.

3. GUDELIS A., DRUTEIKIENE R., LUKSIENE B., GVOZDAITE R., NIELSEN S. P., HOU X., MAZEIKA J., PETROSIUS R. Assessing deposition levels of $55 \mathrm{Fe}, 60$ $\mathrm{Co}$ and $63 \mathrm{Ni}$ in the Ignalina NPP environment. J. Environ. Radioactiv., 101, 464, 2010.

4. BUKHARI A. S., MOHAMED H. E. S., BROOS K. V., STALIN A., SINGHAL R. K., VENUBABU P. Histological variations in liver of freshwater fish Oreochromis mossambicus exposed to 60 Co gamma irradiation. J. Environ. Radioactiv., 113, 57, 2012.

5. ZHAO Y., LI J., ZHANG S., CHEN H., SHAO D. Efficient enrichment of uranium(VI) on amidoximated magnetite/ graphene oxide composites. RSC Adv., 3,18952, 2013.

6. LI J., HU J., SHENG G., ZHAO G.,. HUANG Q. Effect of $\mathrm{pH}$, ionic strength, foreign ions and temperature on the adsorption of $\mathrm{Cu}(\mathrm{II})$ from aqueous solution to $\mathrm{GMZ}$ bentonite.Colloid. Surface A., 349, 195, 2009.

7. OHNUKI T., AOYAGI H., KITATSUJI Y., SAMADFAM M., KIMURA Y., PURVIS O. W. Plutonium(VI) accumulation and reduction by lichen biomass: correlation with U(VI) .J. Environ. Radioactiv., 77, 339, 2004.

8. WANG Q., CHEN L., SUN Y. B. Removal of radiocobalt from aqueous solution by oxidized MWCNT. J. Radioanal. Nucl. Ch., 291, 787, 2012.
9. GUNNARSSON M., JAKOBSSON A. M., EKBERG S., ALBINSSON Y., AHLBERG E. Sorption Studies of Cobalt(II) on Colloidal Hematite Using Potentiometry and Radioactive Tracer Technique. J. Colloid. Interf. Sci., 231, 326, 2000.

10. CHEN H., LI J., SHAO D., REN X., WANG X. Poly(acrylic acid) grafted multiwall carbon nanotubes by plasma techniques for $\mathrm{Co}(\mathrm{II})$ removal from aqueous solution.Chem. Eng. J., 210, 475, 2012.

11. CHEN C., XU D., TAN X., WANG X. Sorption behavior of $\mathrm{Co}$ (II) on $\gamma$-AlO in the presence of humic acid. J. Radioanal. Nucl. Ch., 273, 227, 2007.

12. SONG W., HU J., ZHAO Y., SHAO D., LI J. Efficient removal of cobalt from aqueous solution using $\beta$-cyclodextrin modified graphene oxide. Rsc Adv., 3, 9514, 2013.

13. RENGARAJ S., MOON S. H. Kinetics of adsorption of $\mathrm{Co}$ (II) removal from water and wastewater by ion exchange resins. Water Res., 36, 1783, 2002.

14. XU D., SHAO D., CHEN C., REN A., WANG X. Effect of $\mathrm{pH}$ and fulvic acid on sorption and complexation of cobalt onto bare and FA bound MX- 80 bentonite. Radiochim. Acta., 94, 97, 2006.

15. ZHANG S., NIU H., GUO Z., CHEN Z., WANG H., XU J. Impact of environmental conditions on the sorption behavior of radiocobalt in $\mathrm{TiO}_{2}$ /eggshell suspensions. J. Radioanal. Nucl. Ch., 289, 479, 2011.

16. ZHAO G.X., LI J.X., REN X.M., CHEN C.L., WANG X.K. Few-layered graphene oxide nanosheets as superior sorbents for heavy metal ion pollution management. Environ. Sci. Technol., 45, $10454,2011$.

17. CHANDRA V., PARK J., CHUN Y., LEE J.W., HWANG I.C., KIM K.S. Water-Dispersible Magnetite-Reduced Graphene Oxide Composites for Arsenic Removal. Acs. Nano., 4, 3979, 2010.

18. ROMANCHUK A.Y., SLESAREV A.S., KALMYKOV S.N., KOSYNKIN D.V., TOUR J.M. Graphene oxide for effective radionuclide removal.Phys. Chem. Chem. Phys., 15, 2321, 2013.

19. SHAO D., HOU G., LI J., WEN T., REN X., WANG X. PANI/GO as a super adsorbent for the selective adsorption of uranium(VI). Chem. Eng. J., 255, 604, 2014.

20. ZHANG S., ZENG M., XU W., LI J., LI J., XU J., WANG X. Polyaniline nanorods dotted on graphene oxide nanosheets as a novel super adsorbent for $\mathrm{Cr}(\mathrm{VI})$. Dalton T., 42, 7854, 2013.

21. YANG X., LI J., WEN T., REN X., HUANG Y., WANG X. Adsorption of naphthalene and its derivatives on magnetic graphene composites and the mechanism investigation. Colloid. Surface A, 422, 118, 2013.

22. LONG R., YANG R. Carbon nanotubes as superior sorbent for dioxin removal.J. Am. Chem. Soc., 123, 2058, 2001.

23. WANG X., CHEN C., DU J., TAN X., XU D., YU S. Effect of $\mathrm{pH}$ and aging time on the kinetic dissociation of $243 \mathrm{Am}$ (III) from humic acid-coated gamma- $\mathrm{Al}_{2} \mathrm{O}_{3}$ : a chelating resin exchange study. Environ. Sci. Technol., 39, 7084, 2005.

24. LI J., CHEN S., SHENG G., HU J., TAN X., WANG X. Effect of surfactants on $\mathrm{Pb}(\mathrm{II})$ adsorption from aqueous solutions using oxidized multiwall carbon nanotubes Chem. Eng. J., 166, 551, 2011.

25. SHAO D., HU J., CHEN C., SHENG G., REN X., WANG X. Polyaniline Multiwalled Carbon Nanotube Magnetic Composite Prepared by Plasma-Induced Graft Technique and Its Application for Removal of Aniline and Phenol. J. Phys. Chem. C, 114, 21524, 2010.

26. BRUMFIEL G. Graphene speeds pair to Stockholm win. Nature, 467, 642, 2010. 
27. RAFIEE MA. Graphene-based Composite Materials. Nature, 442, 282, 2006

28. REN X., LI J., TAN X., SHI W., CHEN C., SHAO D., WEN T., WANG L., ZHAO G., SHENG G., WANG X. Impact of $\mathrm{Al}_{2} \mathrm{O}_{3}$ on the aggregation and deposition of graphene oxide. Environ. Sci. Technol., 48, 5493, 2014.

29. YANG X., CHEN C., LI J., ZHAO G., REN X., WANG X. Graphene oxide-iron oxide and reduced graphene oxideiron oxide hybrid materials for the removal of organic and inorganic pollutants. Rsc Adv., 2, 8821, 2012.

30. CHEN H., LI J., REN X., SUN Y., ZHANG S., WEN T., WANG X. Study on the acid-base surface property of the magnetite graphene oxide and its usage for the removal of radiostrontium from aqueous solution. Radiochim. Acta, 101, 785, 2013

31. SHENG G., LI J., SHAO D., HU J., CHEN C., CHEN Y., WANG X. Adsorption of copper(II) on multiwalled carbon nanotubes in the absence and presence of humic or fulvic acids. J. Hazard. Mater., 178, 333, 2010.

32. CHEN C., WANG X. Adsorption of $\mathrm{Ni}$ (II) from Aqueous Solution Using Oxidized Multiwall Carbon Nanotubes. Ind. Eng. Chem. Res., 45, 9144, 2006.

33. ZHANG J., ZHAI J., ZHAO F., TAO Z. Study of soil humic substances by cross-polarization magic angle spinning ja:math nuclear magnetic resonance and pyrolysis-capillary gas chromatography. Anal. Chim. Acta., 378, 177, 1999.

34. HIRATA M., GOTOU T., HORIUCHI S., FUJIWARA M., OHBA M. Thin-film particles of graphite oxide 1: : Highyield synthesis and flexibility of the particles. Carbon, $\mathbf{4 2}$, 2929, 2004

35. TAO Z.Y., ZHANG J., ZHAI J.J. Characterization and differentiation of humic acids and fulvic acids in soils from various regions of China by nuclear magnetic resonance spectroscopy. Ana. Chim. Acta, 395, 199, 1999.

36. HO Y. S., WASE D. A. J., FORSTER C. F. Kinetic Studies of Competitive Heavy Metal Adsorption by Sphagnum Moss Peat. Environ. Technol., 17, 71, 1996.

37. FAN Q.H., TAN X.L., LI J.X., WANG X.K., WU W.S., MONTAVON G. Sorption of Eu(III) on attapulgite studied by batch, XPS, and EXAFS techniques.Environ. Sci. Technol., 43, 5776, 2009.

38. XU D., CHEN C., TAN X., HU J., WANG X. Sorption of Th(IV) on Na-rectorite: Effect of HA, ionic strength, foreign ions and temperature. Appl. Geochem., 22, 2892, 2007.

39. REN X., WANG S., YANG S., LI J. Influence of contact time, $\mathrm{pH}$, soil humic/fulvic acids, ionic strength and temperature on sorption of U(VI) onto MX-80 bentonite. J. Radioanal. Nucl. Ch., 283, 253, 2010.
40. HEARD W.N. Some experiments on the precipitation of suspensoid protein by various ions and some suggestions as to its cause. J Physiol-London, 45, 27, 1912.

41. MERCER K.L., TOBIASON J.E. Removal of Arsenic from High Ionic Strength Solutions: Effects of Ionic Strength, $\mathrm{pH}$, and preformed versus in situ formed HFO.Environ. Sci. Technol., 42, 3797, 2008.

42. LIU X., HUANG YS., LI J.X. Graphene oxides with different oxidation degrees for $\mathrm{Co}(\mathrm{II})$ ion pollution management. Chem. Eng. J. 302, 763, 2016.

43. SACHS S., BERNHARD G. Influence of humic acids on the actinide migration in the environment: suitable humic acid model substances and their application in studies with uranium-a review. J. Radioanal. Nucl. Ch., 290, 17, 2011.

44. HYUNG H., FORTNER J. D., HUGHES J. B., KIM J. H. Natural organic matter stabilizes carbon nanotubes in the aqueous phase.Environ. Sci. Technol., 41, 179, 2007.

45. WANG S. W., HU J., LI J. X., DONG Y. H. Influence of $\mathrm{pH}$, soil humic/fulvic acid, ionic strength, foreign ions and addition sequences on adsorption of $\mathrm{Pb}$ (II) onto GMZ bentonite. J. Hazard. Mater., 167, 44, 2009.

46. ZHAO Y., LI J., ZHAO L., ZHANG S., HUANG Y., WU X., WANG X. Synthesis of amidoxime-functionalized $\mathrm{Fe}_{3} \mathrm{O}_{4} @$ $\mathrm{SiO}_{2}$ core-shell magnetic microspheres for highly efficient sorption of U(VI). Chem. Eng. J., 235, 275, 2014.

47. LANGMUIR I. The Adsorption of Gases on Plane Surfaces of Glass, Mica and Platinum. J. Am. Chem. Soc., 40, 1361, 1918.

48. DEMIRBAS E. Adsorption of cobalt(II) ions from aqueous solution onto activated carbon prepared from hazelnut shells. Adsorpt. Sci. Technol., 21, 951, 2003.

49. CHEN L., HUANG Y., HUANG L., LIU B., WANG G., YU S. Characterization of Co(II) removal from aqueous solution using bentonite/iron oxide magnetic composites. J. Radioanal. Nucl. Ch., 290, 675, 2011.

50. HUANG Y., CHEN L., WANG H.L. Removal of Co(II) from aqueous solution by using hydroxyapatite. J. Radioanal. Nucl. Ch., 291, 777, 2012.

51. ZEIN R., SUHAILI R., EARNESTLY F., INDRAWATI, MUNAF E. Removal of $\mathrm{Pb}(\mathrm{II}), \mathrm{Cd}(\mathrm{II})$ and $\mathrm{Co}(\mathrm{II})$ from aqueous solution using Garcinia mangostana L. fruit shell. J. Hazard. Mater., 181, 52, 2010.

52. QIU W., ZHENG Y. Removal of lead, copper, nickel, cobalt, and zinc from water by a cancrinite-type zeolite synthesized from fly ash. Chem. Eng. J., 145, 483, 2009. 